\title{
Da revolução à regeneração: crônicas de Machado de Assis e de Olavo Bilac sobre a Argentina
}

\author{
From revolution to regeneration: chronics of Machado de \\ Assis and Olavo Bilac about Argentina
}

\author{
João Paulo Coelho de Souza Rodrigues ${ }^{1}$
}

\section{RESUMO}

Ao substituir Machado de Assis como principal cronista do jornal carioca Gazeta de Notícias, Olavo Bilac propôs a seus leitores uma mudança de linguagem literária. Todavia, ele manteve uma das características da crônica de outros escritores do século XIX, sobretudo de Machado de Assis, na tematização dos problemas cotidianos da cidade do Rio de Janeiro. A leitura de algumas crônicas destes dois autores permite iluminar duas interpretações distintas sobre a história argentina, sobre a realidade brasileira e sobre as relações entre Argentina e Brasil, entre a crise final do Império e as reformas urbanas do Rio de Janeiro no início do século XX.

Palavras-chave: Imprensa; Crônica; História política; Reforma urbana; Liberalismo.

Para Sidney Chalhoub

\section{ABSTRACT}

After substituting Machado de Assis as the main columnist of carioca's Gazeta de Notícias newspaper, Olavo Bilac proposed to his public a change in literary language. However, he mantained one of the characteristics of other nineteenth century writers' chronicles, more prominently in Machado de Assis' ones, in terms of the focus on Rio de Janeiro's daily problems. The analysis of some of their columns allow to shadow light two distinct interpretations about Argentinian history, about Brazilian society and about Argentina-Brazil relations, between the final crisis of the Empire regime and the Rio de Janeiro's urban reforms of the beginning of the twentieth century.

Keyword: Press; Chronic; Political history; Urban reform; Liberalism.

1 Departamento de Ciências Sociais, Universidade Federal de São João del Rei. 
No início de 1897, já com carreira literária consagrada, Machado de Assis deixava sua crônica semanal na Gazeta de Notícias do Rio de Janeiro, jornal no qual vinha colaborando desde 1881, e cedia o lugar para um jovem poeta que, dali em diante se destacaria como prolífico cronista: Olavo Bilac, que desde o começo daquela década contribuíra para vários jornais da cidade (incluindo a própria Gazeta). Bilac tentaria manter uma das principais linhas da coluna machadiana, embora viesse a alterar significativamente a linguagem literária utilizada. O então recém eleito presidente da Academia Brasileira de Letras, ao deixar as páginas do jornal (iria publicar algumas crônicas isoladas em 1899 e 1900) punha termo a uma prática iniciada em meados da década de 1870, pela qual a autoria passava para narradores-personagens, com sua psicologia própria, que passavam a ser os titulares de séries completas de crônicas. Tal foi o caso de "Lélio", em "Balas de Estalo" (1883-1886), de "João das Regras", em “A + B" (1886), e de "Policarpo", em "Bons Dias!" (1888-1889). Já em “A Semana" (1892-1897), não há um nome para o narrador, mas os procedimentos estilísticos são os mesmos quanto a uma autoria fictícia. Desta forma, Machado tornava menos unívoca e simplista a interpretação de suas crônicas, optando pela ironia fina e, muitas vezes, pelo sarcasmo dirigido ao próprio leitor (CHALHOUB, 2005, p. 67-74; GRANJA, 1998, p. 67-94; PEREIRA, 2009, p. 9-57). Já Bilac optaria por um discurso direto, na imensa maioria das vezes transparente com o leitor: as inicias "O.B." que seguiam suas crônicas mal disfarçavam quem as escrevia. Além disso, o discurso direto, o forte caráter opinativo, os julgamentos às claras não deixariam dúvidas de que o poeta e jornalista encarava suas crônicas como um instrumento de intervenção sobre o público leitor, uma ferramenta pedagógica, buscando chamar sua atenção para determinados temas e convencê-lo a seguir seus posicionamentos, muitas vezes feitos sem comedimento (DIMAS, 2006c).

Todavia, tanto Machado quanto Bilac fizeram dos problemas da cidade do Rio de Janeiro um personagem constante em suas crônicas, constantemente vinculando tais mazelas com características reprováveis da política, primeiramente imperial e, a seguir, republicana. Bilac, em certo sentido, foi mais longe que Machado neste aspecto: quase sempre que pretendia criticar a capital e seus moradores, mesclava-os num tipo antropomorfizado: "Sebastianópolis".

Bilac também adotaria novos parâmetros, que logo se veriam repercutidos em crônicas, artigos e discursos de outros literatos do Rio de Janeiro da Belle Époque: a comparação. Se Machado utilizava-se de uma zombeteira crítica interna das práticas urbanas, sobretudo dos governantes da cidade, Bilac faria contrastar os modos e costumes de habitantes e de políticos cariocas com modelos externos de civilidade, geralmente europeus. Francófilo como tantos outros literatos brasileiros, Bilac viajou ao menos três vezes a Paris, enviando de lá crônicas que, por mais que apresentassem aqui e ali críticas a aspectos da vida francesa, expressam o deslumbramento pela "Cidade Luz", modelo último de cidade de Bilac e de outros literatos (DIMAS, 2006c, p. 87-102; NEEDELL, 1993, p. 209-269). Contudo, é notável também a presença das referências à capital argentina na sua produção jornalística, e não 
somente na Gazeta de Notícias, pois o país vizinho ao sul rivaliza em termos de referencial nos textos de jornal deste autor, fato que parece se repetir até a Primeira Guerra Mundial. Em um grau bem menor, a Argentina também está presente na produção do seu antecessor.

\section{Liberalismo, instituições e história política}

Em crônica publicada na revista Ilustração Brasileira de 1876, "Manassés" comentava assim a expectativa na cidade do Rio de Janeiro pela chegada da companhia italiana Ferrari: "Antes de ir mais longe, convém advertir que o fato de nos virem as celebridades líricas do Rio da Prata é um fenômeno que, em 1850, seria puramente milagre; mas que hoje, mediante os progressos do dia, parece a coisa mais natural do mundo" (ASSIS, 1997a, p. 14-15).

À primeira vista, a passagem, que serve de preâmbulo para comentários mais detidos sobre a febre por cantores líricos italianos no Rio de Janeiro, sugere que as viagens entre Buenos Aires e a Corte eram mais comuns que no passado. Com efeito, os novos vapores permitiram a criação de companhias de viagens que faziam o trajeto entre o Rio da Prata, o litoral brasileiro e os portos da Europa, de forma mais rápida e confortável do que no quarto de século anterior. Os jornais da época ostentavam dezenas de anúncios de "paquetes" que ligavam Argentina, Uruguai e Brasil a portos como Lisboa, Vigo, Bordéus ou Hamburgo. Mas há também um outro sentido, certamente logo percebido pelo leitor contemporâneo à crônica: a naturalidade com que se viajava de uma cidade a outra.

Ainda que marginal no desenvolvimento geral do texto, o comentário guarda um significado histórico importante; afinal, o autor, na realidade um personagem-narrador inventado por Machado de Assis, está se referindo ao fim de uma época em que a relação entre Argentina e Brasil estivera marcada pelas guerras. $\mathrm{O}$ comentário adquire mais força neste sentido quando se nota que, em crônicas $1^{\circ}$ de setembro de 1876 e de 15 de maio de 1877 (ASSIS, 1997a, p. 25-26; 101), "Manassés" não só faz mais referências a companhias vindas da Itália através de Buenos Aires, como também se mostra em dia com o noticiário dos jornais daquele país. A fácil e recorrente viagem, assim como outras transformações no panorama intelectual brasileiro, como a ascensão do republicanismo, que ativou o interesse de muitos letrados pela realidade dos países sul-americanos (PREUSS, 2011, p. 37-46), atesta não só uma mudança para além da tecnologia dos meios de transporte navais, mas o impacto que ela teve na cultura letrada do final do século XIX.

Todavia, o mote da viagem entre Rio de Janeiro e Buenos estaria presente, de certa forma, em outra crônica de Machado, publicada em 9 de julho de 1888, na Gazeta de Notícias, e intitulada "O futuro dos argentinos". Sua primeira frase revela o claro tom pessoal que marcaria o texto: "Quando hoje contemplo o rápido progresso da nação argentina, recordo-

${ }^{2}$ A série foi publicada entre julho de 1876 e abril de 1878 . Em séries posteriores, Machado inseriria reiteradamente referencias às notícias de jornais argentinos, particularmente o La Nación, que os jornais cariocas reproduziam. 
me sempre da primeira e única vez que vi o Dr. Sarmiento, ${ }^{3}$ presidente que sucedeu ao General Mitre ${ }^{4}$ no governo da República" (ASSIS, 1997b, p. 179). A autoria era identificável ao final pelas iniciais “M. de A." (ASSIS, 1888, p. 1). O estilo não se parecia com o espírito zombeteiro, irônico, até sarcástico e cáustico que seus narradores costumavam adotar, o que dá credibilidade ao caso que a crônica passa a relatar: em 1868, Machado cruzou com Sarmiento quando jantava com amigos (provavelmente jornalistas e escritores). $\mathrm{O}$ importante argentino estava apenas de passagem, vindo dos Estados Unidos, onde era representante diplomático, para sua posse em Buenos Aires. A despeito do rápido encontro, "Naquela visão rápida do presidente eleito pode-se dizer que nos aparecia o futuro da nação argentina" (ASSIS, 1997b, p. 179). O autor joga com o efeito de imediato reconhecimento do leitor que, haja vista a história posterior, deveria saber quem era Sarmiento. Talvez até soubesse que ele tinha sido, antes de ocupar tão alto cargo, um importante jornalista e militante da causa liberal na Argentina. Todavia, a crônica não faz referencia a estes fatos, num silêncio de difícil interpretação, pois Sarmiento esteve pelo menos duas vezes antes de 1868 no Rio de Janeiro e se encontrou com o então jovem imperador Pedro II, sendo por ele condecorado em 1852, durante as negociações do governo brasileiro com os exilados argentinos em Montevidéu e com o governador da província de Entre Rios, Justo José de Urquiza, de uma aliança para derrubar o governador de Buenos Aires, Juan Manuel de Rosas. Não só Sarmiento, mas vários outros escritores, poetas e ensaístas da "geração de 37"5, como Andrés Lamas, José Rivera Indarte, José Mármol, Florencio Varela, Juan Bautista Alberdi, e Juan María Gutiérrez, passaram pelo Rio de Janeiro, alguns dos quais publicaram na imprensa carioca (AMANTE, 2010).

De qualquer forma, qual seria o futuro que é aludido na crônica? Numa volta que, na economia literária do texto, servia para dar o sentido completo do seu entendimento do que seria um "rápido progresso", Machado insere a história no relato de um encontro fortuito entre dois desconhecidos.

Com efeito, uma nação abafada pelo despotismo, sangrada pelas revoluções, na qual o poder não decorria mais que da força vencedora e

\footnotetext{
${ }^{3}$ Domingo Faustino Sarmiento (1811-1888), militar, político, jornalista e ensaísta, esteve exilado durante o governo de Juan Manuel de Rosas (1829-1832 e 1835-1852). Escreveu durante este tempo o Facundo: civilização e barbárie (1845), no qual busca entender as razões do caudilhismo argentino. Foi ácido polemista, e escreveu extensa obra sobre pedagogia, crítica literária, história, entre outros temas. Foi presidente de 1868 a 1874, quando estimulou a imigração europeia e o ensino público.

${ }^{4}$ Bartolomeu Mitre (1821-1906), militar, político e historiador, também esteve exilado durante o governo de Rosas. Foi presidente durante a Guerra do Paraguai, no início da qual liderou as forças da Tríplice Aliança. Na década de 1880 sua influência decai na política nacional, e se dedica sobretudo à imprensa e à pesquisa, fundando o jornal La Nación e escrevendo, entre outros, a principal obra de história argentina até meados do século XX, a História de Belgrano.

${ }^{5}$ A despeito das grandes clivagens existentes entre os autores englobados, a "geração de 37" tem em comum a oposição, em nome de ideais liberais, ao poder de Rosas e dos caudilhos federalistas, que dominaram ou estiveram presentes na vida política argentina da independência à década de 1870 . Todos viveram exilados no Chile, no Uruguai e no Brasil até a derrubada de Rosas em 1852, momento a partir do qual as diferenças políticas internas entre seus membros se acentuaram (SHUMWAY, 2008; WASSERMAN, 1997).
} 
da vontade pessoal, apresentava este espetáculo interessante: um general patriota, que alguns anos antes, após uma revolução e uma batalha decisiva, fora elevado ao poder e fundara a liberdade constitucional, ia entregar tranquilamente as rédeas do Estado, não a outro general triunfante, depois de nova revolução, mas a um simples legista, ausente da pátria, eleito livremente por seus concidadãos (ASSIS, 1997b, p. 179-180).

Este resumo de história política sintetiza o entendimento dominante entre os intelectuais brasileiros anteriores à "geração de 1870" sobre o contraste entre a Argentina e o Brasil, contraste que, na realidade, era ampliado em círculos concêntricos: da Argentina para a região do Prata, de do Prata para a América do Sul ou para a América Espanhola. Quintino Bocaiuva, amigo de Machado, por exemplo, entendia que a história dos povos argentino e uruguaio derivava do descontrole das "paixões" inerentes a suas origens espanholas:

É isso o que se tem podido observar na história das variadas evoluções desses povos, que desde o berço, como o Hércules da mitologia, começaram a lutar com a serpente do despotismo e da conquista até poderem esmagar, no período da sua juventude, a hidra da tirania social alentada pela demagogia (SILVA, 1986, p. 299).

Bocaiuva, assim como Machado, entendia que havia um corte na história Argentina recente que fazia com que ela estivesse abandonando o período das paixões exaltadas. Contudo, se o futuro líder republicano escrevia, em 1870, ${ }^{6}$ com o intuito de aproveitar a recente vitória conjunta sobre o ainda mais tiranizado Paraguai para estreitar os laços entre os antigos inimigos argentinos e brasileiros, para, com o elogio à "regeneração constitucional" que a Argentina vinha experimentando desde 1852 (SILVA, 1986, p. 298), tornar a ideia republicana mais atraente para seu público, Machado exibia, pela mesma época, uma interpretação - se assim se pode dizer - mais nuançada.

A rigor, não se trata de Machado, mas do mesmo "Manassés" que se espantava com a proximidade do Prata trazida pelas companhias marítimas. Em 15 de dezembro de 1876, sua crônica começava com uma tática comum aos narradores machadianos: a tentativa de despistar o leitor via declaração de falta de assunto: "Desta vez a história dos quinze dias dura apenas cinco minutos; falta-me tempo, saúde, vagar e até motivo" (ASSIS, 1997a, p. 59). Apesar da curta crônica efetivamente poder ser lida nos tais "cinco minutos", logo fica claro que assunto havia para um comentário da quinzena. Afinal, como "Manassés" confessa logo a seguir:

6 Tratava-se de conferência intitulada "As instituições e os povos do Rio da Prata", realizada no Teatro de S. Pedro, e publicada como folheto. 
Motivo, não é verdade. Pelo menos a última revolução argentina dava para duas colunas ou pouco menos. As revoluções por aqueles lados fazem o papel das trovoadas que ultimamente surgem na nossa atmosfera. Escurece o ar, aglomeram-se as nuvens, e parece vir o céu abaixo. Qu'en sort-il souvent? Du vent. Às vezes nem isso; uma nação, quatro pingos, duas braças de céu azul e ficamos nós como estávamos.

Havia um tema para uma crônica séria, profunda, sobre política internacional, uma "revolução". Todavia, o narrador logo a colocava em perspectiva, como promessa não cumprida de tempestade. Mais: indicava que esse fato era corriqueiro e sem consequências, e, com isso, rebaixava não só a revolução mais recente, mas a própria Argentina, tratada displicentemente como "aqueles lados". Citando La Fontaine ${ }^{8}$, o país vizinho era comparado à montanha que paria ratos, ou que impressionava, mas que, na verdade, não ameaçava ninguém. Com o trocadilho "souvent/vent", "Manassés" reforça a metáfora atmosférica sobre as revoluções argentinas. Apesar disso, o tema central da crônica seria precisamente este. "Manassés" iria ridicularizar os caudilhos de lá através de um de seus últimos representantes, aquele responsável pelas frustradas "trovoadas".

Foi assim agora. Patatrás! Foge! Foge! Pega! Pega! Aqui del presidente! Santa Maria! Lá vêm eles! Ora pro nobis! Não era uma revolução, era um terremoto, uma cataclismo, uma subversão geral. Sobre a população cai um decreto: estado de sítio a quatro províncias; proclamações; capturas; tropas; cornetas.

Continuando com as eruditas citações em idiomas estrangeiros, outra tática comum dos narradores machadianos, que visavam criar tipos com uma personalidade afrontosa ao leitor, por exigir dele uma ampla gama de conhecimentos, a crônica explicitava os aspectos tangíveis do ocorrido, aspectos que, na sua formalidade ("decreto", "estado de sítio", "proclamações"; capturas"), pareciam indicar uma verdadeira revolução, o que a paródia dos gritos dos argentinos ("Aqui del presidente! Santa Maria”) já mostrava não se tratar. Segue a crônica:

\footnotetext{
7 Alguns dos conflitos vividos pela Argentina no século XIX foram chamados de "revolución" pelos próprios protagonistas, a começar pela "Revolução de Maio" (25 de maio de 1810) que destituiu o Vice-Rei espanhol e deu início ao processo de independência.

8 "Qu'en sort-il souvent? Du vent" (O que resulta frequentemente? Vento) é um trocadilho em francês irreproduzível em português, retirado da fábula de La Fontaine "A Montanha que pare" (fábula 5 do livro 10), que trata de um monte que urra das dores do parto, colocando medo a todos pelo tamanho da cria à qual poderia dar à luz. Todavia, quando se verifica o resultado, vê-se que - e daí vem a expressão - "a montanha pariu um rato". La Fontaine conclui dizendo que aqueles que frequentemente prometem grandes histórias, narrativas e feitos, entregam muitas vezes "vento" (LA FONTAINE, 1877, p. 43).
} 
Logo em seguida anuncia-se que Lopes Jordan [sic] (um Judeu Errante enfadonho com suas invasões periódicas) entrara em Entre Rios. Seus partidários dizem que ele comanda seis mil homens; a gente do governo afiança que apenas comanda quatro homens e dois cavalos. Verifica-se mais tarde que não são quatro, nem seis mil, mas um termo médio de trinta e cinco pessoas. Essas mesmas, depois de alguns tiros, deitam a correr com um exército de seiscentos homens atrás.

E cai o pano. (ASSIS, 1997a, p. 59)

Ricardo López Jordán era um militar de Entre Rios que participou das lutas civis argentinas e uruguaias desde a década de 1840. Foi aliado de Urquiza, até que se rebelou contra ele quando este era governador de Entre Rios, em 1870. Nesta ocasião, homens enviados por Jordán mataram Urquiza e seus dois filhos homens, crime que levou o presidente Sarmiento organizar um exército que sufocou a rebelião. Exilado no Brasil, Jordán invadiria sua província em 1873 e em 1876, sendo em ambas vezes derrotado por tropas do governo central. Este caudilho é um dos últimos líderes dos "federais", que, a despeito de suas diferenças internas, remontavam ao período da independência e que, com grande penetração no interior argentino, eram contra a supremacia política de Buenos Aires, pela livre navegação dos rios (ao que se opunha Buenos Aires como forma de privilegiar as rendas que auferia com sua alfândega) e adeptos de grande autonomia provincial (ROMERO, 2000, p. 63-96). Embora ligados à vida militar e ao campo, seu pensamento político derivava da tradição jurídica espanhola de "soberania dos povos" - pela qual os entes básicos da soberania política eram as cidades e as províncias, que somente poderiam aderir a um estado de livre e expressa vontade - e da teoria do "direito das gentes" - que estabelecia a noção de pacto entre as soberanias definidas territorialmente, assim como o direito irrevogável dos territórios deste tipo à soberania baseado no reconhecimento histórico e nas leis (CHIARAMONTE,2009). Em outras palavras, caudilhos como López Jordán desconfiavam do constitucionalismo de tipo franco-norte-americano, centrado nos direitos individuais dos cidadãos e na formação de Estados com um governo central bem delineado.

"Manassés", todavia, via o lado ridículo das aventuras de Jordán, assemelhadas a uma comédia teatral, tal o exíguo número de adeptos que arregimentava. Seus "trinta e cinco" seguidores serviam bem no papel de "ratos" paridos pela "montanha" revolucionária, que, ainda assim causava gritos assustados. Seguia "Manassés": "Isso em qualquer outro país é apenas um rolo, um regresso de romaria em que trabalham o vinho e as violas. Não é a mesma coisa na região platina, onde Lopes Jordan [sic] tolhe o sono a muita gente. Se lhe dessem uma pensão?" (ASSIS, 1997a, p. 59-60) É de se reparar que o narrador misturava no texto "Prata" e "Argentina" indistintamente. Hábito usual na imprensa e nos documentos oficiais brasileiros, não deixava, por isso mesmo, de ter um significado quanto à identificação da Argentina como uma nação sem o mesmo perfil definido do Brasil, dado por sua estabilidade interna. 
Chegava-se, então, ao final da crônica. O narrador comentava que ao mesmo tempo a Assembleia de deputados do Império começava a se reunir em "sessões preparatórias", sobre as quais nada falaria, assim como sobre "os trabalhos preparatórios" do abastecimento de água para o Rio de Janeiro, afirmação que repetia o tom enganoso do início da crônica. "Manassés", ao contrário, iria comentar também este assunto, ainda que de forma velada, através de uma pequena história. "Manassés" teria encontrado um dos convivas da festa de abertura dos referidos trabalhos, personagem sem nome mas enraivecido pelo engano que teria sofrido. Na ocasião, o encarregado do abastecimento, nas palavras do convidado, "apenas oferece um copo d'água! Se é assim que há de desempenhar seus compromissos..." Ao que termina o narrador, dirigindo-se aos leitores: "Cinco minutos: passem muito bem!" (ASSIS, 1997a, p. 60)

A resolução da crônica se dava no usual estilo zombeteiro dos narradores machadianos dali em diante, no qual o autor presumido ("Manassés") confrontava o leitor com o que seria seu pouco interesse em agradá-lo: finda a narrativa de assuntos sem interesse, ele se despedia sem muita cerimônia. O fecho também levantava a questão do contraste que se pode fazer entre a ridícula Argentina, atravessada de conflitos internos, por menores que fossem, e um Rio de Janeiro em que ocorriam melhoramentos, no qual quem era motivo de riso é o carioca que esperava que antes das obras terminadas já estivesse à disposição água em abundância. Nesse sentido, havia uma interessante inversão ao nível da narração, na medida em que no caso argentino tem-se o choque entre a expectativa de uma história interessante e envolvente e sua não realização, choque que se reproduzia no caso carioca, embora desta vez entre a expectativa do convidado e sua frustração com o "copo d'água". Se pode adicionar que até mesmo os elementos físicos referidos em cada parte da crônica se diferenciam: a "montanha" argentina e a água carioca. Por fim, ainda neste nível literário, havia outra camada de depreciação da história política argentina. A fábula de La Fontaine aludida no trecho em francês tem a seguinte lição de moral: "Quando eu reflito sobre esta fábula,/Cuja narração é mentirosa/E o sentido é verdadeiro,/Eu imagino um autor/Que diz: eu cantarei a guerra/Que fizeram os Titãs contra o senhor do trovão./É prometer muito: mas o que resulta frequentemente?/Vento" (LA FONTAINE, 1877, p. 43). " "Manassés" indica que os jornais começavam, ao se referir às "revoluções" argentina, por contar uma história de "titãs" contra "senhores do trovão", mas, costumeiramente, resultava não mais que "vento". "Manassés" como que se colocava no próprio lugar de La Fontaine, o que remete a algo posteriormente comum nos narradores machadianos: a pretensão de grande sabedoria e erudição, pelo menos em relação aos leitores.

O tom jocoso que servia para zombar da Argentina e da pouca importância de seus fatos políticos, inflacionados por sua constante repetição, desaparecia quando o narrador e os tempos mudavam. Com isso, o sentido que as crônicas davam à história política argentina também mudava, ainda que somente um pouco. Todavia, em "O futuro dos argentinos", de

${ }^{9}$ A tradução é minha. 
1888, Machado ainda reiterava o distanciamento histórico entre um Império constitucional de eleições livres e com paz interna (pelo menos a partir do fim da Regência) e uma nação que menos do que uma história, possuía uma crônica de repetitivos episódios de violência sectária liderados por caudilhos que eram verdadeiros tiranetes. Somente quando passa a tratar do período contemporâneo há uma aproximação da experiência histórica dos dois vizinhos.

A atentar-se bem, Machado parece crer que a história argentina somente começou com a "batalha decisiva" de Pavón (17 de setembro de 1861), que resultou na escolha, no ano seguinte, de Bartolomeu Mitre como presidente da Argentina. Mas há um fato interessante, que o leitor mais erudito de Machado não deve ter deixado passar despercebido, e que representa uma escolha cuidadosa para que a dupla Mitre-Sarmiento possa ser apresentada sob tão louváveis credenciais e o sentido da história argentina ganhar coerência. A rigor, o período constitucional começou após outra batalha, a de Monte Caseros (3 de fevereiro de 1852), que derrubou Rosas. Já no ano seguinte, uma assembleia nacional elaborou uma constituição. Entretanto, a província de Buenos Aires logo se rebelaria, não aceitando alguns aspectos da carta magna. Sob a liderança de Mitre, ela permaneceu de fato fora da Confederação Argentina, chegando a adotar um texto constitucional próprio. A Confederação seria liderada por Justo José de Urquiza, que havia comandado o movimento contra Rosas entre 1851 e 1852, e fora eleito presidente em 1854. Assim, ao menos do ponto de vista formal, o rebelde era Mitre, que somente ascendera à presidência após derrotar Urquiza militarmente. Como resultado, a constituição foi emendada segundo a vontade da província rebelde, o que pavimentou o campo para a eleição do antecessor de Sarmiento.

Somente com essa curiosa interpretação é que é possível afirmar que "esse povo, apesar da escola em que aprendera, tinha a aptidão da liberdade", sendo "claro também, que seus homens públicos em meio das competências que os separavam, e porventura ainda os separam, sabiam unir-se para um fim comum e superior" (ASSIS, 1997b, p. 180), pois essa união não era tão proeminente. Mitre em pessoa sentiu o gosto da rebelião quando, chefiando as tropas aliadas contra o Paraguai, entregou o cargo de comandante a Duque de Caxias para se dedicar a sufocar um levante de algumas províncias do interior argentino. A seguir, Mitre se reconverteria num revolucionário quando, em 1874, pegou em armas contra o presidente Nicolás Avellaneda, que o derrotara nas eleições de 1873.

Contudo, nada disso é levado em conta na narrativa da ascensão argentina.

Vinte anos depois, a nação argentina chegou ao ponto em que se acha, próspera, rica, pacífica, naturalmente ambiciosa de progresso e esplendor. Esqueceu a opressão, desaprendeu a caudilhagem; conhece os benefícios da liberdade e da ordem. Vinte anos apenas; digamos vinte e oito, porque a campanha de Mitre foi o primeiro passo dessa marcha vitoriosa (ASSIS, 1997b, p. 180). 
Após este panorama pela história, Machado terminava a crônica lembrando que havia também passado o tempo de guerras entre os dois países, pois, "em vez de soldados que os vão auxiliar a derrocar uma tirania odiosa, mandamos-lhe uma simples comissão de jornalistas, uma embaixada da opinião à opinião" (ASSIS, 1997b, p. 180). A comissão referida era composta de três jornalistas enviados pelos jornais do Rio de Janeiro em julho de 1888 para prestigiar o aniversário da declaração de independência argentina, comemorada no dia 9 daquele mês (GAZETA DE NOTÍCIAS, 1888, p. 2). ${ }^{10} \mathrm{~A}$ inusitada atitude se explicava pela demonstração de júbilo ocorrida no país vizinho quando lá chegou a notícia da assinatura da Lei Áurea, de tal forma que o governo argentino decretou o dia 17 de maio feriado oficial e os jornais portenhos organizaram uma manifestação pública que percorreu suas redações (no balcão do La Nación discursou Mitre, seu editor) e terminou na frente da representação diplomática brasileira. $O$ jornais cariocas noticiaram as festas com entusiasmo e retribuíram organizando uma homenagem à Argentina no dia 25, data que comemora a Revolução de Maio de 1810, assim como imprimindo edições especiais, o que se repetiu no dia 9 de julho (PREUSS, 2011, p. 47-51). É nessa segunda edição especial que saiu publicado "O futuro dos argentinos".

Dois fatos se imbricavam na referência aos jornalistas enviados a Buenos Aires, revelando um sentido que vinculava os dois países. Na primeira parte da crônica, como mencionado, a história constitucional argentina começara em 1861-1862. Mas ao lembrar as tropas que o Brasil havia enviado para auxiliar Urquiza a derrotar Rosas, Machado, sem evitar totalmente a incoerência cronológica, relembrava o papel civilizador do Império frente à "anarquia" imperante na região do Prata. E ao lembrar a recente aproximação das duas opiniões públicas, só possíveis em países livres, indicava o reposicionamento relativo entre os dois países. Com isso, o significado político da história argentina se encaminhava, no texto, para o fecho, isto é, para se revelar como elevação ao patamar em que se encontrava o Brasil: "Oxalá caminhem sempre o Império e a República, de mãos dadas, prósperos e amigos” (ASSIS, 1997b: 180)"1.

\section{Buenos Aires civiliza o Brasil}

Olavo Bilac concordava com "Manassés" quanto ao caráter pouco sério das revoltas argentinas. Em "Conspirações", crônica publicada na coluna "Registro" do vespertino carioca A Notícia, em 6 de abril de 1905, é com certo grau de ironia que ele afirmava que:

\footnotetext{
${ }^{10}$ Além deles, havia ao menos dois correspondentes de jornais brasileiros em Buenos Aires naquela época (JORNAL DO COMÉRCIO, 1888b, p. 1).

${ }^{11}$ Numa linha similar à de Machado, em que a história da República da Argentina e do Império do Brasil convergem estava o redator Jornal do Comércio do Rio de Janeiro (JORNAL DO COMÉRCIO, 1888a, p. 1).
} 
Está escritos nos livros do Destino que nem em matéria de revolução havemos de ter a hegemonia! Na Argentina e no Uruguai, as revoluções começadas depois da nossa já acabaram, já foram processadas, julgadas e esquecidas: a esta hora, já por lá se cuida de outras novas em folha, cheias de nova importância e de novo interesse (BILAC, 2011, p. 330).

A crônica segue tratando da incapacidade nacional de esquecer as revoltas passadas. $O$ Estado protelava os julgamentos e os jornais continuavam noticiando o andamento dos processos e analisando as consequências políticas. Bilac não estava, obviamente, desejando que o Brasil tivesse um número maior de rebeliões e levantamentos armados. Com sarcasmo, ele pedia aos revolucionários do passado que cedessem a passagem aos revolucionários do futuro, para que os jornais pudessem se dedicar a noticiar os grandes eventos internacionais que ocorriam naquele momento, e sugeria que "os poderes competentes regulassem a matéria, com um decreto" que estipulasse uma fila de espera para revoltas e um tempo para as conspirações, e terminava ironicamente lamentando que essa boa ideia, por ser boa, não seria adotada (BILAC, 2011, p. 331).

Dois anos depois, no mesmo jornal, a crônica "Revoluções sul-americanas" repetia, a respeito de notícias de uma conspiração na província argentina de Santiago del Estero, o enfado quanto à repetição de movimentos políticos que se mostravam meras agitações passageiras, sem maior importância, apesar do interesse dos jornais por noticia-las. Semelhante a "Manassés" em 1876, que fechava o pano da comédia protagonizada por López Jordán, Bilac afirmava: "Parece que se trata da execução de uma ópera ou de uma sessão de cinematógrafo” (BILAC, 2011, p. 446).

O cronista, por esta época, andava entusiasmado com os "progressos" do Rio de Janeiro, creditados por ele à liderança dos governantes, como o ministro da Viação e Obras Públicas Lauro Müller (BILAC, 2011, p. 172-173; p. 457-458), o prefeito Francisco Pereira Passos (BILAC, 2011, p. 323-324; p. 414-415), e à própria república (BILAC, 2011, p. 413-414). Não lhe parecia adequado, portanto, que se perdesse tempo com o passado recente de atribulações que ele entendia se não superado, em vias de o ser. Era preciso enterrar as lutas civis, rebeliões e crises financeiras da década de 1890 no Brasil. Seu sarcasmo era dirigido, portanto, aos jornais e ao público que ainda se atinham a um tempo pretérito, em vez de mirar ao futuro. Era preciso confrontar o leitor de forma a mobilizá-lo para outro tipo de luta: pela regeneração do Rio de Janeiro.

Era com esse afã que Bilac se interessava pela Argentina, cuja metonímia era Buenos Aires. Apesar da permanência de certo ceticismo sobre a qualidade da política argentina, a posição relativa de um país frente ao outro iria se inverter de Machado de Assis a Olavo Bilac, em pouco mais de dez anos. Um novo parâmetro seria estabelecido e, em boa medida, isto coube ao poeta parnasiano. Neste ponto, jogou um papel primordial a visita oficial feita 
em outubro de 1900 pelo presidente Campos Sales à capital Argentina. Acompanhou-o uma comitiva de jornalistas, entre os quais estava o poeta e cronista da Gazeta de Notícias.

Já nos preparativos da viagem Bilac mostrava qual o sentido pedagógico e exemplar a visita teria para seus leitores. A crônica para A Notícia de 21 de agosto daquele ano, apesar de se dirigir a uma hipotética comissão de "senhoras" cariocas que seria recebida por uma contraparte argentina, pretendia, na verdade, preparar o leitor para um contraste chocante.

\begin{abstract}
Mas, ai das minhas gentis patrícias! Buenos Aires é uma das mais lindas, das mais limpas, das mais fidalgas cidades do mundo [...]. Quando voltarem de lá, quando se virem de novo nas apertadas ruas, mal calçadas e mal varridas, de Sebastianópolis, quando compararem o nosso atraso e o nosso desleixo com o conforto e o luxo da capital argentina, sentirão, já não direi a vergonha, mas o desgosto de viver numa cidade que não merece possuir tanta mulher bonita [...] (BILAC, 2011, p. 49)
\end{abstract}

Bilac estabelecia já nessa primeira crônica - de pelo menos uma dezena em que tratou ou mencionou das excelências de Buenos Aires e da Argentina - uma estratégia discursiva sobre a comparação entre as duas nações: o contraste adjetivado entre suas capitais; o apelo aos sentimentos do leitor; e o direcionamento dos enunciados para terceiros. Quanto aos temas, seria comum: a vergonha que se deveria sentir face as condições urbanas do Rio de Janeiro; a elevação de Buenos Aires ao patamar das grandes metrópoles europeias e norteamericanas; o paralelo entre o mal estado de "Sebastianópolis" e os modos descuidados de sua população; e o estabelecimento de um padrão civilizatório referente ao eixo da higiene, ao eixo da beleza e ao eixo do luxo.

Logo a seguir, em 3 de setembro, Bilac trataria de sua ansiedade pelo dia da partida, camuflando-a sob um interesse público que envolveria tanto o autor quanto o leitor pela próxima viagem.

É que essa visita não vai ser apenas uma cortesia e um passeio; vai ser, ou pelo menos deve ser, uma como viagem de instrução. Nós vamos ver de perto, clara e minuciosamente ver o que é uma capital moderna, paciente e carinhosamente embelezada pela fecunda colaboração da energia dos governos e da iniciativa particular. E pasmaremos, decerto, quando verificarmos que o Rio de Janeiro, cotejado com Buenos Aires, é uma cidade, pelo seu atraso material e pela sua absoluta falta de conforto e de elegância, indigna do nosso incontestável adiantamento intelectual e moral (BILAC, 2011, p. 51). 
O uso da primeira pessoa do plural como o sujeito enunciador, se bem fosse comum em suas crônicas, fornecia à visita a Buenos Aires uma clara conotação de experiência coletiva e de experiência pedagógica. Todavia, pela clara opinião de Bilac sobre os méritos argentinos, o aprendizado era dirigido, sobretudo, aos leitores e seus líderes: "O que é preciso pedir aos deuses, é que saibamos aproveitar a viagem, e as sábias lições de que ela será fartamente o pretexto. É preciso que todos nós, os que lá formos, senadores, deputados, homens de imprensa, saibamos e queiramos ver e sentir, estudar e compreender" (BILAC, 2011, p. 52). De sua parte, já convertido ou convencido, Bilac seria apenas o profeta que denunciava os males, apelava à indignação moral e apresentava o modelo de futuro que levaria à redenção de toda uma sociedade. Como tal, entendia a viagem como uma peregrinação.

De volta ao Rio de Janeiro, Bilac alterou ligeiramente seu estilo, refluindo da terceira pessoa do plural para a primeira do singular. O cronista se dirigiu diretamente à capital brasileira, a partir das páginas da Gazeta de Notícias de 18 de novembro de 1900, pedindo que ela não se enraivecesse com as verdades que lhe iria atirar na face, pois aquilo era um ato de amor. E a verdade que deveria ser proferida era que "a vizinhança de Buenos Aires é uma vergonha para ti".

Quem um dia te disse que és a primeira capital da América do Sul zombou da tua ingenuidade e injuriou duramente os teus cabelos brancos; mais te ama e muito mais digno é da tua gratidão quem francamente te diz que és uma cidade de pardieiros, habitada por analfabetos (DIMAS, 2006a, v. 1, p. 383).

Além do velho casario sujo habitado por "analfabetos", a cidade estava cheia de buracos e de vielas. Em contraste, Buenos Aires tinha um moderno porto, ruas largas, palácios, parques e uma rede de esgoto. É certo que o Rio de Janeiro possuía uma exuberante natureza, mas esta lhe havia sido presenteada pela "Sorte". Buenos Aires, ao contrário, havia trabalhado duro para construir seus parques bem arborizados. $O$ trabalho então, era a via para a civilização. $O$ carioca há tempos sentia vergonha de sua cidade quando voltava da Europa, mas isso não tivera nenhum efeito até aquele momento.

Mas reconhecer a gente que ali assim, a quatro dias de viagem há uma cidade como Buenos Aires, - e que nós, filhos da mesma raça e do mesmo momento histórico com muito mais vida, com muito mais riqueza, com muito mais proteção da Natureza, ainda temos por capital da República, em 1900, a mesma capital de D. João VI em 1808, - isso dói 
como uma afronta, isso é o que revolta como uma injustiça (DIMAS, 2006a, v. 1, p. 385) ${ }^{12}$.

Bilac projetava no carioca seus próprios sentimentos, em boa medida exagerados, pois a primeira crônica que escrevera da cidade para a Gazeta de Notícias, em outubro de 1900, foi uma das poucas vezes que se permitiu o uso da auto-ironia, criando um diálogo telefônico fictício com a redação do diário, no qual a admiração de todos os correspondentes aparece como um pouco ridícula (DIMAS, 2006a, v. 1, p. 380-383). Todavia, Bilac não se conteve, e numa crônica recheada de exclamações e perguntas retóricas, tal como se discursasse para uma plateia, apresentou o exemplo: "Quando Alvear ${ }^{13}$ quis realizar o seu sonho radiante, não houve casmurrice apatacada que ousasse opor-se ao soberano poder da sua vontade". A viagem de estudos, rendia um fruto novo para o peregrino-profeta: era necessário um prefeito que se parecesse com o intendente. "Quem sabe? De um instante para outro o teu Alvear nascerá e tu renascerás, desgraçada cidade que ainda não tiveste quem te soubesse amar mais com atos do que com palavras!" (DIMAS, 2006a, v. 1, p. 385) A crônica, portanto, apresentava uma diretriz para a transformação do Rio de Janeiro: a nomeação de um líder como o fora para Buenos Aires Torcuato de Alvear, com plenos poderes para derrubar propriedades sem o intercurso de medidas legais protelatórias, e com o objetivo de higienizar a cidade, de forma a deixa-la bela e luxuosa. Não se pode dizer que Bilac tenha errado muito nesta profecia ou que os agradecimentos posteriores a Pereira Passos fossem protocolares.

Mas antes que a oportunidade se apresentasse, Bilac teria que lidar com o próprio processo político de "nascimento" e de ação do Alvear carioca. Quando Pereira Passos foi nomeado prefeito, em janeiro de 1903, Bilac dedicou uma crônica na Gazeta de Notícias para comentar (e talvez influir) a administração municipal. Referindo-se à reprodução no Jornal do Comércio de um programa de ação do novo prefeito prevendo uma remodelação geral da cidade e dos órgãos da prefeitura, logo em seguida desmentida pelo próprio Pereira Passos, Bilac aproveitou como gancho uma expressão usada pelo jornal ao qualificar a plataforma de ação apresentada - "quixotesca" (DIMAS, 2006a, v. 1, p. 524) - para propor ao novo edil o papel que deveria desempenhar: "Se S. Ex. quer achar um modelo na epopeia de Cervantes, não hesite, seja D. Quixote, e não queira ser Sancho Pança!" (DIMAS, 2006a, v. 1, p. 524) Bilac entendia que havia uma oposição entre os dois famosos personagens literários, com o cavaleiro representando a nobre procura pelo ideal e pela perfeição e seu escudeiro significando a cautela, o preconceito e, por isso, a recusa ao progresso.

12 Outra menção de vergonha em relação aos argentinos pode ser encontrada em crônica na Gazeta de Notícias de 21 de junho de 1903 (DIMAS, 2006a, v. 1, p. 566).

${ }^{13}$ Torcuato de Alvear (1822-1890) foi prefeito de Buenos Aires entre 1883 e 1887, quando dirigiu um amplo processo de reformas urbanas da cidade. Sobre os princípios aplicados e os poderes de que Alvear gozou, ver Braun (1996, p. 31-71). 
O ideal pode ser, às vezes, a precipitação, a imprudência, a loucura: mas é sempre o progresso, a invenção, a beleza, a iniciativa, o desejo da perfeição.

Sancho Pança deixaria o Rio de Janeiro no estado atual; D. Quixote cumpriria o programa apócrifo que o próprio Jornal do Comércio renegou.

D. Quixote foi o Barão de Haussman que reformou Paris; D. Quixote foi o Marquês de Pombal que das cinzas de uma Lisboa medonha arrancou uma Lisboa airosa; D. Quixote foi o grande Alvear que criou Buenos Aires! D. Quixote foi o espírito yankee que em menos de um século encheu de cidades maravilhosas todo o território dos Estados Unidos... (DIMAS, 2006a, v. 1, p. 525).

A tática envolvida aqui era menos seduzir o prefeito do que criar uma corrente de opinião que empurrasse quem, ao fim e ao cabo, ainda era uma incógnita para o caminho correto. Portanto, Bilac precisava recorrer a modelos outros mais concretos do que o fictício personagem espanhol, entre os quais se destaca, pelo adjetivo, Alvear, que, mais que reformar, "criou" toda uma cidade. O modelo argentino era inescapável, ainda que um dos elementos que ele destacara na crônica de 3 de setembro de 1900 publicada em A Notícia - o papel da "iniciativa particular" - desaparecesse.

Bilac tinha uma clara perspectiva estética do urbanismo almejado. Se as medidas profiláticas possuíam um nítido caráter prático, de resolver os embaraços ao desenvolvimento trazidos pelas doenças endêmicas que assolavam a capital, a abertura de bulevares, a construção de palácios e parques pretendia criar um novo ambiente, propício a novos hábitos de sociabilidade. A vergonha civilizava, mas a civilização somente começaria a se instalar quando existissem espaços onde ela pudesse vicejar e, mais do que revelar praticidade, eles precisariam estar imbuídos de um espírito novo, ser um ideal de uma nova vida. Portanto, em Bilac, não é tão importante frisar os avanços institucionais ${ }^{14}$ ou econômicos argentinos, ${ }^{15}$ e sim a urbanidade, entendida de forma ampla. Em 1903, em $A$ Notícia, surgia uma rara ampliação do panorama, que descortinava algo além da criação de um ambiento urbano civilizado. A propósito de um telegrama do Jornal do Brasil sobre mais uma construção suntuosa a ser erguida em Buenos Aires, Bilac tece uma consideração sobre o progresso argentino. $\mathrm{O}$ autor reproduzia o que seria o muxoxo dos patriotas sobre a imprevidência argentina frente ao hábito de economizar do brasileiro. Isto requeria, pela falta de tino, uma resposta, posto que:

${ }^{14} \mathbf{E}$ curioso como Bilac, grande denunciador do analfabetismo, praticamente não mencione o sistema de ensino argentino, ao contrário de Artur Dias e de Mário Brant, dois jornalistas que também viajaram a Buenos Aires no início do século XX e publicaram narrativas a respeito (DIAS, 1901; BRANT, 1982). Em crônica de 1906 há uma rápida referência à vergonha brasileira frente à "instrução pública" argentina (BILAC, 2011, p. 202)

${ }^{15} \mathrm{Em}$ 1896, em A Bruxa, Bilac lamentou que os imigrantes europeus terminassem em sua grande maioria na Argentina (DIMAS, 2006b, v. 2, p. 27). 
Em virtude da sua megalomania, os argentinos possuem lindas cidades, higiene, política, lavoura próspera, indústria adiantada; e que nós, apesar da nossa prudência e da nossa economia, não temos finanças mais equilibradas que as deles.

Porque é esta, meus amigos, a feia e triste verdade. Eles estão em más condições financeiras, mas souberam empregar o seu dinheiro: e nós, que não estamos em condições melhores, esbanjamos o nosso em despesas de que não ficou vestígio, e não temos um só dos palácios, uma só das avenidas, um só dos portos que eles têm, - como não temos exércitos e esquadra que possam competir com a esquadra e o exército dos vizinhos. (BILAC, 2011, p. 201) ${ }^{16}$

Mas sua pauta de assuntos após 1900 foi marcada pela tônica da reforma urbana do Rio de Janeiro. Passados os anos de seguidas crises agudas dos primeiros governos republicanos, com a desilusão relativa ao confronto político, abriu-se espaço para a noção da administração isenta da sociedade, baseada em conceitos comuns relativos ao "progresso", à "higiene", e à "beleza" (BENCHIMOL, 1992). ${ }^{17}$ Como escreveu Bilac em crônica publicada em 10 de novembro de 1906 em A Notícia, "de 1894 a 1898 foi pacificado o Brasil; de 1898 a 1902 foi restaurado o seu crédito - e de 1902 a 1906 houve aqui tantos e tais progressos materiais e morais, que chegam a causar assombro" (BILAC, 2011, p. 413). Ainda que esta seja uma projeção em retrospectiva de uma trajetória histórica que ia da anarquia à civilização, a frase expressa o cuidado de Bilac ao criticar os governantes e em se imiscuir na política. É de se notar também que se na década de 1890 o poeta fora um dos perseguidos pela repressão do governo de Floriano Peixoto, no início da década seguinte ele clamava por homens providenciais de punho forte, no modelo do argentino Alvear.

Durante os anos de reforma de "Sebastianópolis", Bilac se entusiasmaria com as melhorias urbanas feitas, mas continuaria insistindo no paralelo com Buenos Aires, como que a não deixar espaço para ilusões. Afinal, o slogan desta época - "O Rio civiliza-se"18 revelava o caráter de processo inconcluso. Em crônica de 1906 na Kósmos, o poeta-jornalista se felicitava que a população da cidade tivesse colaborado com o recenseamento municipal, o que, segundo ele, nunca fora feito antes por falta de civismo. E identificava no espírito de competição com Buenos Aires a razão para a súbita onda patriótica.

\footnotetext{
${ }^{16}$ Desde a Revolta da Armada de 1894 discutia-se a reforma da marinha brasileira, em especial a compra de novos navios. o conflito diplomático entre Argentina e Chile sobre limites fronteiriços, em 1902, que levou a uma pequena corrida armamentista entre os dois países, a crise do Acre com o Peru e a Bolívia entre 1899 e 1903, e os efeitos estratégicos navais da Guerra Russo-Japonesa de 1904-1905, levaram a que o assunto fosse visto como emergencial. A partir de então, e com o estímulo do Ministério das Relações Exteriores, o Congresso, ao longo de vários anos, passou a discutir reformas e aprovar verbas para a compra de armamentos para as forças armadas, sobretudo para a Marinha (BUENO, 2003; MARTINS FILHO: 2010).

${ }^{17}$ Sidney Chalhoub argumenta que tal “ideologia” já esta presente desde a década de 1870 (CHALHOUB, 1996).

${ }^{18}$ Subtítulo da coluna "O Binóculo" de Alberto Figueiredo Pimental na Gazeta de Notícias. Pimentel, junto com jornalistas como Luís Edmundo e escritores como Coelho Neto, fundou a "Liga Contra o Feio" (1908) e a "Liga da Defesa Estética" (1915).
} 
Não! A nossa boa vontade, o nosso auxílio, a nossa colaboração eficaz e entusiástica, nasceram única e exclusivamente disto: do desejo, que todos nutríamos, de dar um quinau a Buenos Aires, e de pregar uma boa peça ao nosso, já agora famoso, amigo Carrasco, Estatístico-Mor da cidade portenha, e contador milagroso, que trata os algarismos do Censo como Jesus tratava os peixes na Judéia, multiplicando-os prodigiosamente (DIMAS, 2006b, v. 2, p. 368) ${ }^{19}$.

Ainda que Bilac se juntasse ao ceticismo generalizado na imprensa do período quanto ao vertiginoso crescimento populacional da capital argentina, ironizado, sobretudo nas revistas ilustradas (CARETA, 1909; O MALHO, 1906ab) ${ }^{20}$ ele via com bons olhos o espírito de competição, pois ele estimulava o correto comportamento da população, o que, por seu turno, facilitava a administração da vida urbana, municiada, como tinha que ser, de dados estatísticos exatos, completos e abrangentes. Se nesta questão não bastava a autoridade do prefeito Passos, vinha em seu socorro a vergonha pela superioridade portenha.

Mas o que era esperança redentora em 1900, exposta com um discurso desabrido e corajoso, se tornaria também motivo de incômodo, como se vê, por exemplo, em crônica de 18 de janeiro de 1908. Naquele ano, nas páginas do Correio Paulistano, um dos maiores incentivadores do papel regenerador do exemplo argentino expressaria preocupação com a "mórbida mania" nacional de se preocupar com a imagem do Brasil no país vizinho. ${ }^{21}$ Como que a se defender de um tribunal patriótico, Bilac justificava suas invectivas anteriores ao estado do Rio de Janeiro e suas comparações com Buenos Aires como o amor de um apaixonado pela cidade, que "ardentemente" (DIMAS, 2006b, v. 2, p. 126) desejava sua regeneração, explicação que recuperava o tema da dedicação contido na crônica de 18 de novembro de 1900 publicada na Gazeta de Notícias. Com efeito, havia nas crônicas de Bilac um prurido em não apresentar ou não se preocupar com a opinião estrangeira sobre o Rio de Janeiro ou sobre o Brasil, pois sua estratégia parecia ser a de envergonhar não pelo julgamento externo, mas pela vergonha gerada por um despertar da consciência pública, que fosse fruto tanto da experiência direta de contato quanto pelos simples relatos do progresso de outros lugares. Todavia, em qualquer dos dois casos, persistia um elemento em comum: a ânsia de imitar movida pela reprovação. Além disso, o próprio cronista usaria o recurso que criticava. Em 8 de abril de 1904, nas páginas de $A$ Notícia desprezaria a fama da Baía de Guanabara de "mais bela baía do mundo" (BILAC, 2011, p. 239) com o argumento de que no estrangeiro, em especial na Argentina, ela era tida como mal sinalizada e perigosa para os navios. Portanto, era irônico que Bilac tratasse "essa singularíssima vigilância internacional" como coisa de "conselheiro Acácio". "Mas o conselheiro Acácio" - arrematava - "era um idiota" (DIMAS, 2006b, v. 2, p. 125).

\footnotetext{
${ }^{19}$ O autor se refere a Gabriel Carrasco, diretor da Oficina Demográfica Nacional argentina entre 1899 e 1906.

${ }^{20}$ Nenhuma destas revistas possui paginação.

${ }^{21}$ Esta crônica retoma o tema de outra publicada em 19 de setembro de 1902 em A Notícia(BILAC, 2011, p. 159-160).
} 
É provável que esta fosse a opinião de Lima Barreto sobre Bilac. Ao menos, é certo que ele detestava a "mórbida mania" argentinófila. Acérrimo crítico da maioria dos escritores laureados da sua época, seja por suas "panelinhas literárias", seja por seus vínculos com as redes de sociabilidade das elites cariocas e o que ele via como desprezo pela sorte dos pobres, também desgostava da reurbanização da Capital Federal. Barreto acusava, em crônica de julho de 1911 na Gazeta da Tarde, os adeptos do "bota-baixo", que abriu a Avenida Central, destruiu o casario colonial e ergueu prédios em estilo neoclássico, art-nouveau e eclético, de desfigurarem a cidade de seus aspectos originais e históricos em prol da mera imitação de uma cidade que não condizia com o contexto brasileiro ${ }^{22}$.

É que eles estavam convencidos da sua fealdade, da necessidade do seu desaparecimento, para que o Rio se aproximasse mais de Buenos Aires. A capital da Argentina não nos deixa dormir. Há conventos de fachada lisa e monótona nas suas avenidas? Não. Então esse casarão deve ir abaixo (RESENDE, 2004a, p. 99).

Lima Barreto enumerava, em outra crônica de 1915 no Correio da Noite, os principais itens da mania de imitação derivada da inveja: ter uma capital de um milhão de habitantes, com longas e largas ruas retas (RESENDE, 2004a, p. 166) ${ }^{23}$, e ter grandes palácios. Contudo seguia a crítica - tudo o que se conseguia era uma cidade de aspecto falsificado, o que significava feiura. Ou, trocando em miúdos: "um Rio-Paris barato ou mesmo Buenos Aires de tostão" (RESENDE, 2004a, p. 100).

\section{Conclusão}

Secundária na obra de Machado de Assis, central na de Olavo Bilac, as referencias à Argentina revelam contrastes na forma pela qual se podem ler nos dois autores entendimentos distintos da relação entre aquele país e o Brasil entre o final do século XIX e a primeira década do século XX. O uso por Machado de um narrador com personalidade própria lhe permite, na década de 1870 , reproduzir um entendimento mais ou menos difundido entre a elite letrada brasileira com relação à anarquia que caracterizaria os países sul-americanos e, por conta disso, certo sentimento de superioridade. O Império era uma ilha de civilização e unidade em meio ao despotismo e a desagregação (MATTOS, 2000, p. 6881). Já na década seguinte o sentimento muda ou, pelo menos, parece menos seguro de si.

\footnotetext{
${ }^{22}$ Em seu clássico estudo sobre as reformas urbanas do início do século XX, Larry Benchimol sugere que os dois fatores que as impulsionaram naquele momento, apesar dos projetos virem da década de 1880 , foram a estabilidade política, a visita de Campos Sales a Buenos Aires em 1900 e os elogios a esta cidade pela imprensa (BENCHIMOL, 1992, p. 200).

${ }^{23}$ A crítica, a rigor, começara já em seu primeiro romance, de 1909, pela voz do narrador, seu alter-ego (BARRETO, 1984, p. 100).
} 
Sem que o Brasil abdique de sua posição, ela não lhe é mais única e privilegiada. A Argentina já se iguala no campo institucional e avança em termos de progresso material.

Com Olavo Bilac emerge uma outra relação. Parte de uma geração que se inicia no jornalismo na passagem do Império para a República, participando da campanha abolicionista, por exemplo, e que de imediato se vê jogada no meio dos conflitos que agitaram a primeira década republicana, Bilac, como outros colegas seus, reflui do comentário político. Entre vários literatos do período, decai a crença de que o jornalismo pode contribuir para reformar as instituições. O ideal missionário aprofunda-se em tendência já presente no jornalismo anterior de difusão dos "corretos" hábitos sociais e, em Bilac, encontra um porto convidativo na ideia de regeneração urbana do Rio de Janeiro. E se, para outros autores do período a Argentina como país é um polo de atração, com suas administrações, suas ferrovias, e sua imigração europeia, entre outros, para Bilac o objeto é mais restrito: Buenos Aires, a "Paris da América", como escreve em 3 de setembro de 1900 em A Notícia(BILAC, 2011, p. 52).

Assim, enquanto Machado encontra na história política do país vizinho um símbolo, primeiro de comicidade, e depois de progresso, Bilac circunscreve o símbolo a uma cidade, cujo significado também é de progresso, mas não mais político, e sim de hábitos sociais. De certo modo, este símbolo é de segunda ordem, no sentido de pretender remeter a um símbolo maior - Paris. Já em Machado, se há um modelo, este é o próprio Brasil, na forma da história do Império. Percebe-se, portanto, que entre 1870 e 1910 a Argentina, como signo, possibilitou um jogo de inversões de significados culturais e políticos na crônica brasileira, que se inseriam em uma rede mais ampla de autores que ainda cabe explorar para melhor compreender não só o desenvolvimento deste gênero literário e jornalístico, mas as posições desses autores sobre alguns dos temas que agitaram a imprensa durante a passagem do século XIX para o XX.

\section{Referências}

AMANTE, Adriana. Poética y políticas del destierro: argentinos en Brasil en la época de Rosas. Buenos Aires: Fondo de Cultura Económica, 2010.

ASSIS, Machado de. O futuro dos argentinos. Gazeta de Notícias, Rio de Janeiro, 9 jul. 1888. p. 1

_. História de quinze dias. São Paulo: Globo, 1997a.

Obras completas: balas de estalo e crítica. São Paulo: Globo, 1997b. 
BAGGIO, Kátia Gerab. A "outra" América: a América Latina na visão dos intelectuais brasileiros das primeiras décadas republicanas. 1998. Tese (Doutorado em História) Universidade de São Paulo, São Paulo.

BARRETO, Lima. Recordações do escrivão Isaías Caminha. São Paulo: Ática, 1984.

BENCHIMOL, Jaime Larry. Pereira passos: um Haussmann tropical (a renovação urbana da cidade do Rio de Janeiro no início do século XX). Rio de Janeiro: Secretaria Municipal de Cultura, Turismo e Esportes, 1992.

BILAC, Olavo. Registro: crônicas da Belle Époque carioca. Campinas: Unicamp, 2011.

BRANT, Mario. Viagem à Argentina. 2. ed. Rio de Janeiro: Fundo Editorial AAFBB, 1982.

BUENO, Clodoaldo. Política externa da Primeira República: os anos de apogeu (de 1902 a 1918). Rio de Janeiro: Paz e Terra, 2003.

CARETA. A população de Buenos Aires. Careta, Rio de Janeiro, n. 79, 1909.

CHALHOUB, Sidney. Cidade febril: cortiços e epidemias na corte imperial. São Paulo: Companhia das Letras, 1996.

. A arte de alinhavar histórias: a série "A+B" de Machado de Assis. In: CHALHOUB, Sidney; NEVES, Margarida de Souza; PEREIRA, Leonardo Affonso de Miranda (Org.). História em cousas miúdas: capítulos de história social da crônica no Brasil. Campinas: Unicamp, 2005. p. 67-85.

CHIARAMONTE, José Carlos. Cidades, províncias, estados: origens da nação argentina (18001846). São Paulo: Hucitec, 2009.

DIAS, Artur. Do Rio a Buenos Aires. Rio de Janeiro: Imprensa Nacional, 1901.

DIMAS, Antonio. Bilac, o jornalista: crônicas. Campinas: Unicamp, 2006a. v. 1. . Bilac, o jornalista: crônicas. Campinas: Unicamp, 2006b. v. 2. . Bilac, o jornalista: ensaios. Campinas: Unicamp, 2006c.

GRANJA, Lúcia. A língua engenhosa: o narrador de Machado de Assis, entre a invenção da história e a citação da história. In: PEREIRA, Leonardo de Miranda Affonso; CHALHOUB, Sidney (Org.). A história contada: capítulos de história social da literatura no Brasil. Rio de Janeiro: Nova Fronteira, 1998. p. 67-94.

Nove de julho. Jornal do Comércio, Rio de Janeiro, 9 jul. 1888a. p. 1. 
Telegramas. Jornal do Comércio, Rio de Janeiro, 9 jul. 1888b. p. 1.

LA FONTAINE, Jean de. Oeuvres de J. de la Fontaine: théatre, fables, poésies, etc. Paris: Laplace, 1877.

MARTINS FILHO, José Roberto. A marinha brasileira na era dos encouraçados, 1895-1910: tecnologia, forças armadas e política. Rio de Janeiro: FGV, 2010.

MATTOS, Ilmar Rohloff de. "Um país novo": a formação da identidade brasileira e a visão da Argentina. In: FUNDAÇÃO ALEXANDRE DE GUSMÃO. A visão do outro: seminário BrasilArgentina. Brasília: Funag, 2000, p. 57-95.

O MALHO. Em Buenos Aires: escola de recenseadores. O Malho. Rio de Janeiro, ano 5, $\mathbf{n}^{\circ} 209$, 1906a.

. Em Buenos Aires: outro congresso de notáveis. O Malho. Rio de Janeiro, ano $5, \mathrm{n}^{\circ} 211,1906 \mathrm{~b}$.

PEREIRA, Leonardo de Miranda Affonso. Introdução. In: ASSIS, Machado de. História de quinze dias. Campinas: Unicamp, 2009. p. 9-57.

_ _ _ _ . Em Buenos Aires: outro congresso de notáveis. O Malho, Rio de Janeiro, ano 5, n. 211, 1906.

NEEDELL, Jeffrey. Belle Époque tropical: sociedade e cultura de elite no Rio de Janeiro na virada do século. São Paulo: Companhia das Letras, 1993.

PREUSS, Ori. Bridging the island: Brazilian's views of Spanish America and themselves, 1865-1912. Madri: Iberoamericana, 2011.

RESENDE, Beatriz; VALENÇA, Rachel (Org.). Toda crônica: Lima Barreto. Rio de Janeiro: Agir, 2004a. v. 1.

Toda crônica: Lima Barreto. Rio de Janeiro: Agir, 2004b. v. 2.

RODRIGUES, João Paulo Coelho de Souza. A dança das cadeiras: literatura e política na Academia Brasileira de Letras (1896-1913). Campinas: Unicamp, 2001.

ROMERO, José Luis. Breve historia de la Argentina. 7. ed. Buenos Aires: Fondo de Cultura Económica, 2000.

SEVCENKO, Nicolau. Literatura como missão: tensões sociais e criação cultural na Primeira República. São Paulo: Brasiliense, 1983. 


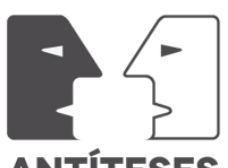

ANTÍTESES

SHUMWAY, Nicolas. A invenção da Argentina: história de uma ideia. Brasília: UnB, 2008.

SILVA, Eduardo (Org.). Ideias políticas de Quintino Bocaiuva. Brasília: Senado Federal, 1986. v. 1.

SODRÉ, Nelson Werneck. História da imprensa no Brasil. Porto Alegre: EdiPUCRS, 2011. -

WASSERMAN, Fabio. La generación de 1837 y el proceso de construcción de la identidad nacional argentina. Boletín del Instituto de Historia Argentina y Americana Dr. Emilio Ravignani, Buenos Aires, n. 15, p. 7-34, 1997. 


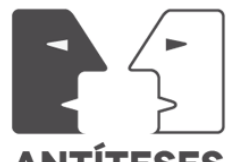

Recebido em: 01/04/2013

Aprovado em: 31/05/2013 